\title{
Isotope amount ratio measurement challenge
}

\author{
Olaf Rienitz $^{1} \cdot$ Axel Pramann ${ }^{1}$
}

(C) Springer-Verlag Berlin Heidelberg 2016

We would like to invite you to participate in the Analytical Challenge, a series of puzzles to entertain and challenge our readers. This special feature of "Analytical and Bioanalytical Chemistry" has established itself as a truly unique quiz series, with a new scientific puzzle published every other month. Readers can access the complete collection of published problems with their solutions on the ABC homepage at http://www. springer.com/abc. Test your knowledge and tease your wits in diverse areas of analytical and bioanalytical chemistry by viewing this collection.

In the present challenge, isotope amount ratios is the topic. And please note that there is a prize to be won (a Springer book of your choice up to a value of $€ 100)$. Please read on...

\section{Meet the challenge}

Isotope amount ratios play an important role in several scientific fields, ranging from geochemistry [1] to food safety [2] and from meteorology [3] to metrology [4]. Usually, relative deviations from internationally agreedupon reference materials (so-called delta-zero materials) appear to be fit for purpose [5]. Nevertheless, isotope ratios that are accurate on an absolute scale are

Olaf Rienitz

olaf.rienitz@ptb.de

1 Physikalisch-Technische Bundesanstalt, Bundesallee 100, 38116 Braunschweig, Germany indispensible in some cases. Unfortunately, mass spectrometers yield signal intensity ratios that are related to the isotope ratios but are frequently biased due to inherent properties of the mass spectrometers (so-called mass bias). Therefore, the measured isotope ratios must be calibrated [6]. Determination of the calibration factors, and hence the absolute isotope ratios, is best achieved using gravimetrically prepared mixtures of at least two distinct isotopically enriched materials [7]. Depending on the number of isotopes involved, the mathematical solutions become rather complex, and for several decades iterative calculations were thought to be unavoidable in this context. In the meantime, analytical solutions have been derived [8].

\section{The challenge}

In a cupboard in your laboratory, you find two bottles (let's call them A and B) containing solutions of copper. The label of bottle A reads " $w(\mathrm{Cu})=851.63 \mu \mathrm{g} / \mathrm{g}, x\left({ }^{63} \mathrm{Cu}\right)>0.99 \mathrm{~mol} /$ mol," and the label of B states " $w(\mathrm{Cu})=725.47 \mu \mathrm{g} / \mathrm{g}$, $x\left({ }^{65} \mathrm{Cu}\right)>0.97 \mathrm{~mol} / \mathrm{mol}$ " (see Fig. 1).

Unfortunately, at this very moment your boss enters the laboratory, notices the two bottles, and says: "Excellent, you've already found them! Would you please be so kind as to determine the exact isotopic composition of copper in each solution?" After recovering from the encounter, you remember that isotope mixtures can be used to figure out absolute isotope ratios. So you take the $m_{\mathrm{A}}=2.2561 \mathrm{~g}$ solution from bottle A and mix it in a third bottle (AB) with the $m_{\mathrm{B}}=2.6432 \mathrm{~g}$ solution from bottle B. After allowing for complete 


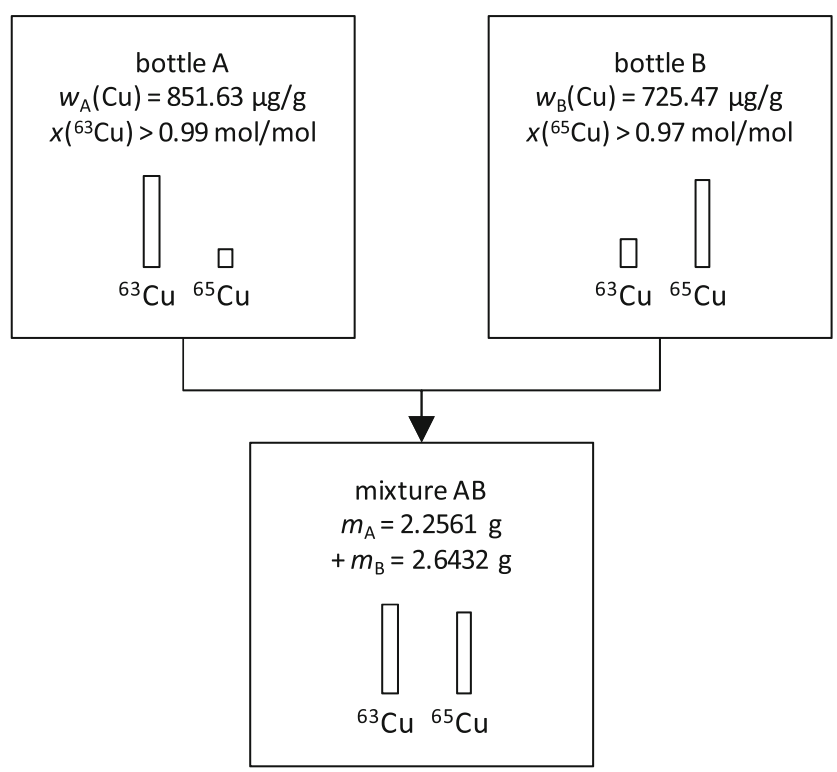

Fig. 1 Mixing scheme

equilibration of the isotopes in bottle $\mathrm{AB}$, you perform thorough mass spectrometric measurements of the three solutions, yielding the following signal intensity ratios:

$r_{\mathrm{A}}=I_{\mathrm{A}}\left({ }^{65} \mathrm{Cu}\right) / I_{\mathrm{A}}\left({ }^{63} \mathrm{Cu}\right)=0.00370125 \mathrm{~V} / \mathrm{V}$,

$r_{\mathrm{B}}=I_{\mathrm{B}}\left({ }^{65} \mathrm{Cu}\right) / I_{\mathrm{B}}\left({ }^{63} \mathrm{Cu}\right)=48.6537 \mathrm{~V} / \mathrm{V}$, and

$r_{\mathrm{AB}}=I_{\mathrm{AB}}\left({ }^{65} \mathrm{Cu}\right) / I_{\mathrm{AB}}\left({ }^{63} \mathrm{Cu}\right)=0.985414 \mathrm{~V} / \mathrm{V}$.

In order to correct these measured intensity ratios, you need a calibration factor $K$ which allows you to calculate the absolute isotope amount ratios $R_{i}$ :

$R_{i}=\frac{n_{i}\left({ }^{65} \mathrm{Cu}\right)}{n_{i}\left({ }^{63} \mathrm{Cu}\right)}=K \times r_{i} \Rightarrow K=\frac{R_{\mathrm{A}}}{r_{\mathrm{A}}}=\frac{R_{\mathrm{B}}}{r_{\mathrm{B}}}=\frac{R_{\mathrm{AB}}}{r_{\mathrm{AB}}}$

Here, $n$ denotes the amount of substance and $i$ the bottle identifier A, B, or AB. You also know the relations between the isotope ratios and the isotopic abundances (the amount fractions) $x_{i}$ :

$x_{i}\left({ }^{63} \mathrm{Cu}\right)=\frac{1}{1+R_{i}} \quad x_{i}\left({ }^{65} \mathrm{Cu}\right)=\frac{R_{i}}{1+R_{i}}$

The isotope mixture (AB) was meant to help you. Therefore, you calculate its theoretical (true) isotope ratio:

$R_{\mathrm{AB}}=\frac{n_{\mathrm{AB}}\left({ }^{65} \mathrm{Cu}\right)}{n_{\mathrm{AB}}\left({ }^{63} \mathrm{Cu}\right)}=\frac{n_{\mathrm{A}}\left({ }^{65} \mathrm{Cu}\right)+n_{\mathrm{B}}\left({ }^{65} \mathrm{Cu}\right)}{n_{\mathrm{A}}\left({ }^{63} \mathrm{Cu}\right)+n_{\mathrm{B}}\left({ }^{63} \mathrm{Cu}\right)}$

The amount of ${ }^{65} \mathrm{Cu}$ isotope in mixture $\mathrm{AB}$ originating from bottle $\mathrm{A}\left(n_{\mathrm{A}}\left({ }^{65} \mathrm{Cu}\right)\right)$ can be expressed via the isotopic abundance of ${ }^{65} \mathrm{Cu}$ in bottle $\mathrm{A}\left(x_{\mathrm{A}}\left({ }^{65} \mathrm{Cu}\right)\right)$ and the total amount of copper in mixture $\mathrm{AB}$ from bottle A $\left(n_{\mathrm{A}}\right)$ as

$n_{\mathrm{A}}\left({ }^{65} \mathrm{Cu}\right)=x_{\mathrm{A}}\left({ }^{65} \mathrm{Cu}\right) \times n_{\mathrm{A}}$

The total amount of copper in mixture $\mathrm{AB}$ from bottle $\mathrm{A}$ $\left(n_{\mathrm{A}}\right)$ can be rewritten using the molar mass of copper in bottle $\mathrm{A}\left(M_{\mathrm{A}}\right)$ and the total mass of copper in mixture $\mathrm{AB}$ from bottle $\mathrm{A}\left(m_{\mathrm{A}}(\mathrm{Cu})\right)$ :

$n_{\mathrm{A}}=\frac{m_{\mathrm{A}}(\mathrm{Cu})}{M_{\mathrm{A}}}$

The total mass of copper in mixture $\mathrm{AB}$ from bottle $\mathrm{A}$ $\left(m_{\mathrm{A}}(\mathrm{Cu})\right)$ is defined by the mass fraction of copper in bottle $\mathrm{A}\left(w_{\mathrm{A}}\right)$ and the mass of the solution from bottle $\mathrm{A}\left(m_{\mathrm{A}}\right)$ you used to prepare mixture $\mathrm{AB}$ :

$m_{\mathrm{A}}(\mathrm{Cu})=m_{\mathrm{A}} \times w_{\mathrm{A}}$

The molar mass of copper in bottle A $\left(M_{\mathrm{A}}\right)$ can be calculated from the molar masses of the isotopes and their respective amount-of-substance fractions:

$M_{\mathrm{A}}=x_{\mathrm{A}}\left({ }^{63} \mathrm{Cu}\right) \times M\left({ }^{63} \mathrm{Cu}\right)+x_{\mathrm{A}}\left({ }^{65} \mathrm{Cu}\right) \times M\left({ }^{65} \mathrm{Cu}\right)$

To solve this challenge, you may use the following values: $M\left({ }^{63} \mathrm{Cu}\right)=62.929598 \mathrm{~g} / \mathrm{mol}$ and $M\left({ }^{65} \mathrm{Cu}\right)=64.927790 \mathrm{~g} / \mathrm{mol}$ [9]. The following additional advice might also be helpful. Starting from Eq. 3, you should replace all quantities on the righthand side of the equation using Eqs. 4-7 and Eq. 2 until only the masses $\left(m_{i}(\mathrm{Cu})\right)$, the molar masses $\left(M_{i}\right)$, the mass fractions $\left(w_{i}\right)$, and the isotope amount ratios $\left(R_{i}\right)$ remain. Then you should use Eq. 1 and replace the isotope amount ratios $\left(R_{i}\right)$ with the signal intensity ratios $\left(r_{i}\right)$ and the calibration factor $K$.

(1) Obtain the analytical equation for $K$ in terms of known/ measured quantities

(2) Obtain the numerical value of $K$

(3) Now you should be able to do what your boss asked you to do and calculate the isotopic abundances of copper-63 and copper- 65 in bottles A and B.

\section{References}

1. Valley JW, Cole D (eds.). Stable isotope geochemistry. Reviews in mineralogy and geochemistry. Washington, DC: Mineralogical Society of America; 2001. ISBN 0939950-55-3. 
2. van Leeuwen KA, Prenzler PD, Ryan D, Camin F. Gas chromatography-combustion-isotope ratio mass spectrometry for traceability and authenticity in foods and beverages. Compr Rev Food Sci Food Saf. 2014;13:814-37.

3. Gorski G, Strong C, Good SP, Bares R, Ehleringer JR, Bowen GJ. Vapor hydrogen and oxygen isotopes reflect water of combustion in the urban atmosphere. Proc Natl Acad Sci USA. 2015;112(11): 3247-52.

4. Bettin $\mathrm{H}$ et al. Improved measurement results for the Avogadro constant using a ${ }^{28}$ Si-enriched crystal. Metrologia. 2015;52:360-75.

5. Brand WA, Coplen TB, Vogl J, Rosner M, Prohaska T. Assessment of international reference materials for isotope-ratio analysis. IUPAC technical report. Pure Appl Chem. 2014;86(3):425-67.

6. Meija J. Calibration of isotope amount ratios by analysis of isotope mixtures. Anal Bioanal Chem. 2012;403:2071-6.

7. Nier A. A redetermination of the relative abundances of the isotopes of carbon, nitrogen, oxygen, argon, and potassium. Phys Rev. 1950;789-793.

8. Mana G, Rienitz O. The calibration of Si isotope ratio measurements. Int J Mass Spectrom. 2010;291:55-60.
9. Wang M, Audi G, Wapstra AH, Kondev FG, MacCormick M, Xu X, et al. The AME2012 atomic mass evaluation (II). Table, graphs, and references. Chin Phys C. 2012;36:1603-2014.

We invite our readers to participate in the Analytical Challenge by solving the puzzle above. Please send the correct solution to abcchallenge@springer.com by October 1,2016. Make sure you enter "Isotope amount ratio measurement challenge" in the subject line of your e-mail. The winner will be notified by e-mail and his/her name will be published on the "Analytical and Bioanalytical Chemistry" homepage at $\mathrm{http}: / / \mathrm{www} . s p r i n g e r . c o m / a b c$ and in the journal (volume 409/issue1), where readers will find the solution and a short explanation.

The next Analytical Challenge will be published in 408/27, November 2016. If you have enjoyed solving this Analytical Challenge you are invited to try the previous puzzles on the ABC homepage. 